\title{
An Exploratory Study on Blended Skills Quotient as a pedestal to uphold Automation in Future Jobs
}

\author{
${ }^{1}$ Ms Devika Dhumal, ${ }^{2}$ Ms. Dipti Kandari, \\ ${ }^{1,2}$ Assistant Professor, Department of Soft Skills, Dr. D. Y Patil College of Architecture Pune, India. \\ devika.capture@gmail.com
}

Dr. Shalaka Parker - Department of Soft Skills \& Dean MBA, D. Y. Patil Master of Computer

Applications and Management Pune, India, dean_mba@dypimca.ac.in.

Mrs. Viral S Ahire, Assistant Professor, D. Y. Patil Master of Computer Applications and

Management Pune, India, viral.ahire30@gmail.com

\begin{abstract}
The wave of Industry 4.0 is engulfing the globe, leading to a transformation that is percolating and influencing the other ambits of life, especially the academia. However, this shift has marked a great gap between the requisites of the technologically driven industry and the curriculum and pedagogical processes practiced in the higher education institutions. As a consequence, a lack of competencies and skills of the graduates has been observed that adversely affects their employability as well as the productivity in the professional market. Owing to the same, this paper aims to comprehend Industry 4.0 and its requisites for the graduates, in order to explore solutions and techniques in the form of a Blended Intelligence Quotient Model to inculcate fusion skills and higher order cognitive abilities in the curriculum of the HEIs to sustain and excel in the domain of automation for the future workforce
\end{abstract}

Keywords - Industry 4.0, blended skills, soft skills, graduates, automation, intelligence Quotient Model.

\section{INTRODUCTION}

Each time the digital wave starts knocking against the door of technology, it creates a powerful ripple effect that encapsulates several elements that get engulfed and get recognized as novel determinants under what is referred today to as Industry 4.0. The magnanimity of the transformation caused by this industrial technological revolution continues to bookmark more and more requisite factors that could be placed under the umbrella term of global employability. The rate at which industry 4.0 is marking its territory at a global forefront, the industries have now revamped their expectations and evaluation processes of hiring their prospective employees. The fourth industrial revolution has formulated an ecosystem for an idyllic hotbed of inventions and has paved its roots to transport technology beyond human intervention through digital and mechanical ambits like Big Data and Analytics, Simulation, the industrial Internet of Things, Horizontal and Vertical System Integration, Cyber Security, Artificial Intelligence, Automation and Robotics, Cloud Computing, Augmented Reality, and Additive Manufacturing, to name a few.

\section{NATURE OF INDUSTRY 4.0 AND ITS EXPECTATIONS FROM THE GRADUATES}

This manufacturing revolution will increase productivity, shift economics, foster industrial growth, and modify the profile of the workforce -ultimately changing the competitiveness of companies and regions. [1] This 360 degree shift has not only modified the essence of technology in the human sphere, but also has, in turn, challenged, questioned and almost transmuted the professional existence and role of humans in the "smart" industrial domain.

Though the industry has faced an exponential paradigm shift from mechanization and electrical to automation and digitalization, its parallel counterpart, the academic sphere, continues to function on the conventional framework of the dissemination of knowledge. To elaborate, the up gradations of pedagogical processes and curriculum have demonstrated a relaxed increase in the developmental graph as compared to the industry for which the academia aspires to train its graduating students. According to Tom Puthiyamadam , Global Digital Services Leader with PwC's Advisory, “As AI begins to impact the workforce and automation replaces some existing skills, we're seeing an increased need for emotional intelligence, creativity, and critical thinking, for instance." [2] Consequently, the scope and expectations of the modern industrial market from their employees have 
metamorphosed from a majorly technical- based to a cognitive- ability based model. LinkedIn, a professional networking site, recognizes this attribute based mutation and defines the emerging Engineer 4.0 as "An open and active person who likes variety, both in terms of contacts with people and of tasks. They have the ability to communicate very technical, detailed information to others with enthusiasm and optimism which inspires in listeners positive feelings about the idea which they talk about. They attach great importance to detail and strive for perfection. They produce high quality of work and adhere to standards. They comply with the rules and procedures. The Engineer 4.0 , in addition to consistently relevant technical competence, must be aware of the importance of all the competencies we have described. So equipped they can go out with confidence to meet the challenge of the era of Industry 4.0." [3] It is thereby evident that the cognitive skills based curriculum is the linking trajectory between the academic and the industrial arena and hence, should be revamped and customized according to the expectations of the upcoming Industry 4.0 and to survive in the era of automation to combat the challenges that it would pose for the human workforce. "Based on the results, the nontechnical skills which are demanded by employers are communication skills especially in English, teamwork skills, critical thinking and problem-solving skills, entrepreneur skills and computer skills. Universities should be exposed their students with much more of interdisciplinary teaching, research, innovation and valuable industrial training to meet current demands of industries." [4]

\section{REQUISITE SKILLSET FOR THE FUTURE WORKFORCE OF 2030}

According to McKinsey Global Institute Workforce Skills Model, automation and artificial intelligence would accelerate a shift in skills that the workforce would ideally require in the future. This case study classifies the future workforce skills into five distinct categories being physical and manual, basic cognitive skills, higher cognitive skills, social and emotional, and technological. The statistics put forth by this research highlight that automation has successfully facilitated the requisite workforce skillset of the Lower Order Thinking Skills (LOTS), i.e. The former two categories mentioned above. They expound that the physical and manual workers in the US were likely to see a decrease of $11 \%$ from the 90 billion hours worked in 2016, while Western Europe's 113 billion hours would be reduced by $16 \%$. The number of hours devoted to basic cognitive skills in the US was 53 billion in 2016, with $14 \%$ fewer needed in 2030, and Western Europe's 62 billion hours would be cut by $17 \%$. [5] The statistics put forth by this research highlight that automation has successfully facilitated the requisite workforce skill set of the Lower Order Thinking Skills (LOTS), ie. the former two categories mentioned above. However, on the contrary, with respect to the latter three skills, there was a noticeable increase in the number of hours devoted by the employees to the stipulated task. This, in turn, proves the need to manage the Higher Order Cognitive Skills (HOCS) and to create "soft" employees to combat challenges that automation poses for the potential labor force. Retraining employees for specific technology or STEM skills is more apparent today than figuring out how to upgrade or impart "soft skills" such as empathy, managing others, and communication, or "intrinsic skills" such as critical thinking or creativity. Making progress in these latter categories of skills will become increasingly important for companies and, more broadly, for educators.[6]In this era, even though an extensively technologically advanced one, the industry's exigencies have radically inclined towards the non-technical and soft skills to mark the evolutionary trend of Industry 4.0. While stakeholders of the Higher Education Institutions too, are emphatic about training students in the domain of the core technical skills, the global industrial market claims otherwise, thus leading to an evident misalliance between what the graduates possess and what they actually require to implement in their professional sphere. According to a survey conducted by the Department of Soft Skills, D.Y. Patil Educational Complex, Akurdi, Pune, wherein the Human Resource Managers and recruiters of the various reputed companies like Tata Consultancy Services, Bombardier, LTI, Network Labs(India. pvt. ltd), Accenture and Cap Gemini were interviewed through a questionnaire on the expectations from the future workforce, it was observed that $94.48 \%$ of the recruiters and professionals were seeking to hire candidates possessing excellent soft skills rather than technical skills. The primary conclusion of the study was that the education sector should concentrate more on enhancing the soft skills and other related cognitive skills in the graduating populace to render them employable and tailor them to encounter the jeopardies of the automation centered future. Furthermore, while automation is taking over the world and posing a threat to human employability and progressing to a level where human intervention would be eliminated completely, it is the HOCS that would function hand in hand with automation and artificial intelligence and come to the rescue to sustain the challenges that automation would pose for humankind. It would be this assemblage of higher order skill quotients that would not only aid the graduates of the Higher Education Institutions in job acquisition but also to survive in the highly automated driven realm.

\section{DEVELOPING HIGHER ORDER COGNITIVE SKILLS THROUGH THE BLENDED INTELLIGENCE QUOTIENT MODEL (BIQM)}

Owing to the gap between the curriculum and pedagogy in the HEIs, and the expectations of the new industry, the peril 
of unemployment, especially in developing countries like India, has been on the rise. India\&\#39;s rate of unemployment doubled in the past two years, according to the State of India's Environment (SoE) In Figures, 2019 which has had an adverse impact on global productivity. [7] According to SoE in Figures, a major cause for high unemployment rates in India is the lack of skills required for jobs that are available. The Union Ministry of Skill Development and Entrepreneurship says $4.69 \%$ of India's total workforce is formally skilled, as against $52 \%$ in the United States, $68 \%$ in the United Kingdom, $75 \%$ in Germany, $80 \%$ in Japan and 96\% in South Korea. [8] With the objective of bridging the aforementioned gap and preparing the graduates of the HEIs of India for Industry 4.0, the paper proposes a Blended Intelligence Quotient Model to enhance and enable their employability in tandem with requisites of the latest industrial market. The BIQ Model has been formulated to skill two subjects namely, the faculty and the graduating students of the HEIs of India to produce graduates with the ideal attributes required to function alongside and efficiently with machines. The BIQ

Model is an input process output model constituting the following five Blended Skills that have been identified as the most indispensable skills that graduates need to acquire in the academia before entering the industry and also to be more qualitatively eligible to be globally employable: Gab Intelligence, Innovation Intelligence, Emotional Intelligence, Professionalism and Rational Quotient as shown in figures 1 and 2. A recent study showed that the absence of excellence among lecturers is related to the idea that lecturers have not sufficiently obtained soft skills during their own learning in higher education institutions. As stated by Salleh, Sulaiman, and Talib (2010), soft skills are the most operative instruments and methods for higher

education institutions to appraise the future capabilities of lecturers\&\#39; and students. Therefore, recognizing and evolving the importance of soft skills acquisition has been a thought- provoking task for curriculum designers (Hodges\&amp; Burchell, 2003). [9]

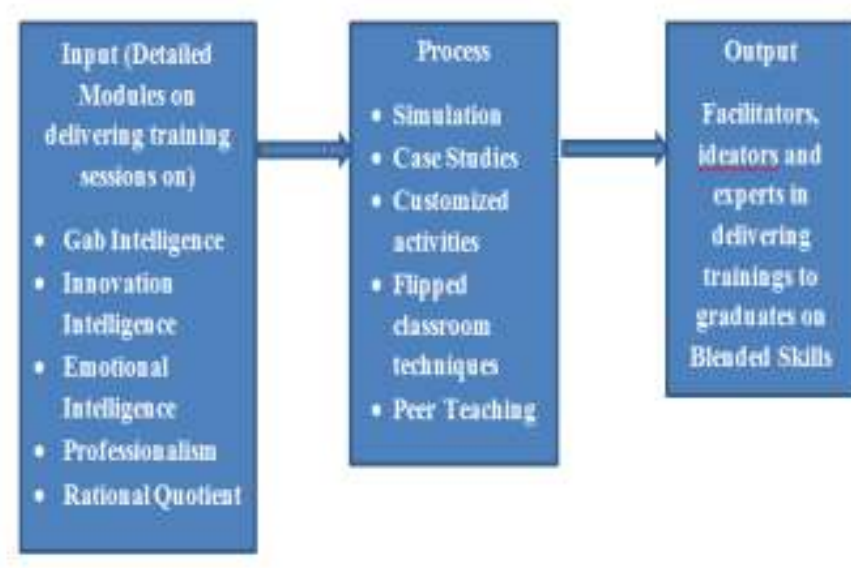

Fig. I Blended lantelizgace Quotient Model for Faraulty

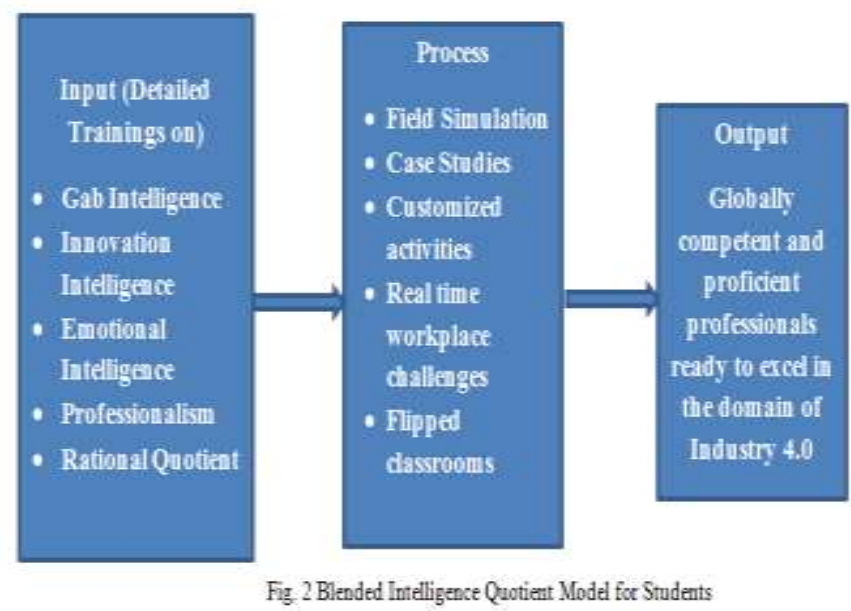

Firstly, with respect to the faculty members of HEIs, an exhaustive and all-encompassing training module package comprising of the segments mentioned above with the aim of delivering these blended skills to the students has been designed as the input for the skill acquisition training model as shown in fig. 1 . These modules specifically pertain to and are a proportional mélange of knowledge, skills and attitudes (KSAs) and revolve around functioning via five phases namely, analysis, design, development, execution and evaluation of each of the intelligence quotients. [10] The input of these phases is followed by the implementation of the same as a process through the medium of classroom simulations, case studies, execution of detailed lesson plans, customized activities, pragmatic approaches and flipped classroom techniques. Consequently, the output of these embedded processes would be to be skilled facilitators to impart the learned fusion intelligence to the students and render them excellent professionals in the framework of industry 4.0 and thus, employable. Furthermore, these "skilled" faculty members intricately dovetail the input process for the student that is proportionally inclusive of the technical and non- technical attributes and skill sets that are indispensable for the graduates of today's technologically urbanized era. Figure 2 demonstrates the Blended Intelligence Quotient Model specially curated for students to sustain and attain an expertise in the emerging trends in computation and technology and develops levels of intelligence that would run parallel to artificial intelligence.

To conclude, the process of the implementation of the Blended Intelligence Quotient Model for the students follows a highly transitional modus operandi wherein there is a radical shift from theoretical to a more experiential and industrially inclined approach towards generating the above mentioned set of skills and attributes. The pedagogical techniques constitute simulated workplace environments, working in tandem with technology and acquired cognitive skills, experiential learning through real time professional situations, and people skills enhancement. Therefore, this model of teaching learning process triggers the nurturing 
and enrichment of the requisite exigencies of industry 4.0 in the form of perfectly assimilated abilities like effective communication skills, creativity and out-of-the-boxthinking, empathy, stress and time management, social skills, work ethics, business etiquette, advanced critical and analytical thinking, higher order problem solving and decision making skills. All the aforementioned techniques of embedding the Blended Skills within the teachers and ultimately the students, would revolve around the fact that soft employees are the need of the day and that soft intelligence is the aspect that would work create a pedestal to support artificial intelligence and lead the world to an evolutionary state of excellence.

\section{REFERENCES}

[1] Boston Consulting Group, "Embracing Industry 4.0 and Rediscovering Growth.", Bcg.com ,2019. [Online]. Available: https://www.bcg.com/enin/capabilities/operations/embracing-industry-4.0rediscovering- growth.aspx . [Accessed Nov. 13, 2019].

[2] (10) D. Mcginnis, "What is the Fourth Industrial Revolution" salesforceblog,2018 [Online]. Available: https://www.salesforce.com/blog/2018/12/what-is-thefourth- industrial-revolution-4IR.html [Accessed Apr.29,2020].

[3] G. Jaroslaw, "How to Develop Engineers (of Industry) 4.0?" LinkedIn, Jan. 31, 2017. [Online] Available: www.linkedin.com/pulse/how-develop-engineers-industry40- jaroslaw-gracel . [Accessed Nov. 15, 2019].

[4] M. Khair Noordin, "Towards_Industrial_Revolution_40_Employers\& \#39;_Expectations_o n_Fresh_Engineering_Graduates”, Research Gate, 2018. [Online]. Available: https://www.researchgate.net/publication/329356058_Tow rds_Industrial_Revolution_40_Employers\&\#39;_Expectatio ns_on_Fresh_Engineering_Gr aduates . [Accessed Apr. 29, 2020].

[5] A. Jezard, "The 3 key skill sets for the workers of 2030.", June 1, 2018. [Online].Available: https://www.weforum.org/agenda/2018/06/the-3-skill-sets workers- need-to-develop-between-now-and-2030/ [Accessed Nov. 20, 2019].

[6] J. Bughin, E. Hazan, S. Lund, P. Dahlstrom, A. Weisinger, and A. Subramaniam, 2018. "MGI skill shift automation and the future of the workforce." [ebook] Mc Kinsey \&amp; Company, p.57. Available at: https://www.mckinsey.com/ /media/mckinsey/featured\%20i nsights/future $\% 20$ of $\% 20$ organizations/skill\%20shift $\% 20$ aut omation $\% 20$ and $\% 20$ the $\% 20$ future $\% 20$ of $\% 20$ the $\% 20$ workf orce/mgi-skill-shift- automation-and-future-of-theworkforce-may-2018.ashx .

[7] K. Pandey, and R. Sengupta, "State of India's Environment 2019: In Figures.”, 2019. [ebook] Down to Earth, pp.110-111. Available at: https://www.downtoearth.org.in/reviews/state-of-india-senvironment-2019-in-figures-ebook--64926.

[8] K. Pandey, "India's unemployment rate doubled in two years: SoE in Figures.”, Downtoearth.org.in., 2019 [Online] Available:https://www.downtoearth.org.in/news/economy/in dia-s- unemployment-rate-doubled-in-two-years-soe-infigures-64953.[Accessed Nov. 18, 2019].

[9] K. Tang, "The importance of soft skills acquisition by teachers in higher education institutions", Kasetsart Journal of Social Sciences, 2018, [Online] Available: https://doi.org/10.1016/j.kjss.2018.01.002

[10] S. Chand, "Models of Training Employees: Steps, Transitional and Instructional System Development Model." Your Article Library, 2019 [Online]. Available: http://www.yourarticlelibrary.com/training-

employees/models-of-training-employees-steps-transitional and- instructional-system-development-model/29548. [Accessed Nov. 18, 2019]. 